\title{
High-fat diet attenuates the improvement of hypoxia-induced pulmonary hypertension in mice during reoxygenation
}

\author{
Koichi Sugimoto ${ }^{1,2^{*}}$, Tetsuro Yokokawa ${ }^{1,2}$, Tomofumi Misaka1, Takashi Kaneshiro' , Akiomi Yoshihisa', \\ Kazuhiko Nakazato ${ }^{1}$ and Yasuchika Takeishi ${ }^{1}$
}

\begin{abstract}
Background: It is widely recognized that metabolic disorder is associated with pulmonary hypertension (PH). It is known that hypoxia-induced elevated pulmonary artery pressure in mice returns to normal pressure during reoxygenation. However, it is still unclear how metabolic disorder affects the reverse remodeling of pulmonary arteries. In this study, we investigated the effects of high-fat diet (HFD) on the decrease in pulmonary artery pressure and reverse remodeling of pulmonary arteries in mice with hypoxia-induced $\mathrm{PH}$.
\end{abstract}

Methods: We used female C57BL/6 mice aged 8 weeks. After being exposed to hypoxia (10\% oxygen for four weeks) to induce $\mathrm{PH}$, the mice were returned to normoxic conditions and randomized into a normal diet (ND) group and HFD group. Both groups were fed with their respective diets for 12 weeks.

Results: The Fulton index and right ventricular systolic pressure measured by a micro-manometer catheter were significantly higher in the HFD group than in the ND group at 12 weeks after reoxygenation. The medial smooth muscle area was larger in the HFD group. Caspase-3 activity in the lung tissue of the HFD group was decreased, and the apoptosis of pulmonary smooth muscle cells was suppressed after reoxygenation. Moreover, the expression levels of peroxisome proliferator-activated receptor- $\gamma$ and apelin were lower in the HFD group than in the ND group.

Conclusions: The results suggest that metabolic disorder may suppress pulmonary artery reverse remodeling in mice with hypoxia-induced $\mathrm{PH}$ during reoxygenation.

Keywords: Pulmonary hypertension, Reverse remodeling, Obesity, Metabolic disorder, Hypoxia, Apoptosis

\section{Introduction}

Hypoxia-induced pulmonary hypertension $(\mathrm{PH})$ is a very prevalent form of $\mathrm{PH}$ in humans [1]. Hypoxia induces pulmonary vasoconstriction and pulmonary artery remodeling, which is characterized by organic stenosis due to abnormal proliferation of pulmonary artery

*Correspondence: ksugi@fmu.ac.jp

2 Department of Pulmonary Hypertension, Fukushima Medical University, Hikarigaoka 1, Fukushima 960-1295, Japan

Full list of author information is available at the end of the article smooth muscle cells [2, 3], whose mechanisms are not yet thoroughly understood.

It is known that hypoxia-induced elevated pulmonary arterial pressure in mice returns to normal pressure during reoxygenation $[4,5]$. It is reported that increased pulmonary smooth muscle cell apoptosis and mitochondrial function were associated with pulmonary arterial reverse remodeling by reoxygenation $[4,6]$.

Several studies have reported that metabolic disorder is associated with $\mathrm{PH}[7,8]$. Peroxisome proliferatoractivated receptor- $\gamma$ (PPAR- $\gamma$ ), an important key molecule for metabolic syndrome, plays a crucial role in the 
pathogenesis of $\mathrm{PH}$ [9-11]. Alastalo et al. reported that PPAR- $\gamma / \beta$-catenin axis upregulates apelin that induces pulmonary smooth muscle cell apoptosis [11].

However, it is still unclear how metabolic disorder affects the reverse remodeling of pulmonary arteries. In this study, we investigated the effects of high-fat diet (HFD) on the decrease in pulmonary artery pressure and reverse remodeling of pulmonary arteries using mice with hypoxia-induced $\mathrm{PH}$.

\section{Methods}

\section{Animals and ethics statement}

Littermate female C57BL/6 mice aged eight weeks (body weight range: $18.1-20.0 \mathrm{~g})$ were used. The mice were housed with food and water ad libitum at room temperature at a 12:12 light-dark cycle. The investigations conformed to the Guidelines for the Care and Use of Laboratory Animals published by the US National Institutes of Health (NIH publication, 8th Edition, 2011). Our research protocol was approved by the Fukushima Medical University Animal Research Committee. The study on animals was carried out in compliance with the ARRIVE guidelines (Additional file 1). All efforts were made to minimize the suffering of animals, all of which were sacrificed by cervical dislocation after the experiments.

\section{Animal experiment}

The experimental protocol is shown in Fig. 1. Experiment 1: The mice were exposed to hypoxic ( $10 \%$ oxygen) or normoxic conditions for four weeks, during which they were given a normal chow. Thereafter, we evaluated the right ventricular systolic pressure (RVSP), right ventricular hypertrophy $(\mathrm{RVH})$, expression of some associated molecules, and histological features. Experiment 2: The mice were exposed to hypoxic condition (10\% oxygen) for four weeks, during which they were given a normal chow. Then, normoxia was resumed, and the mice were divided by a person, who was blinded to the investigation, into two groups; the ND group mice were fed with a normal diet (CLEA Rodent Diet CA-1, CLEA Japan Inc., Tokyo, Japan), while the HFD group mice were fed with HFD (High Fat diet 32, CLEA Japan Inc.) for 12 weeks (Table 1). The oxygen concentration of hypoxia was determined based on a previous study [4]. The required sample size was estimated to be 10-20 per group based on the number within the range reported in previous studies [12,13]. The used animal number was described in each figure legend. The total number of animals used

Experiment 1
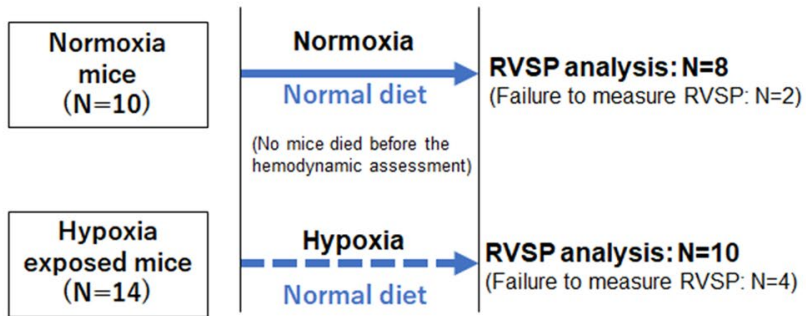

$8 w$

$12 \mathrm{w}$

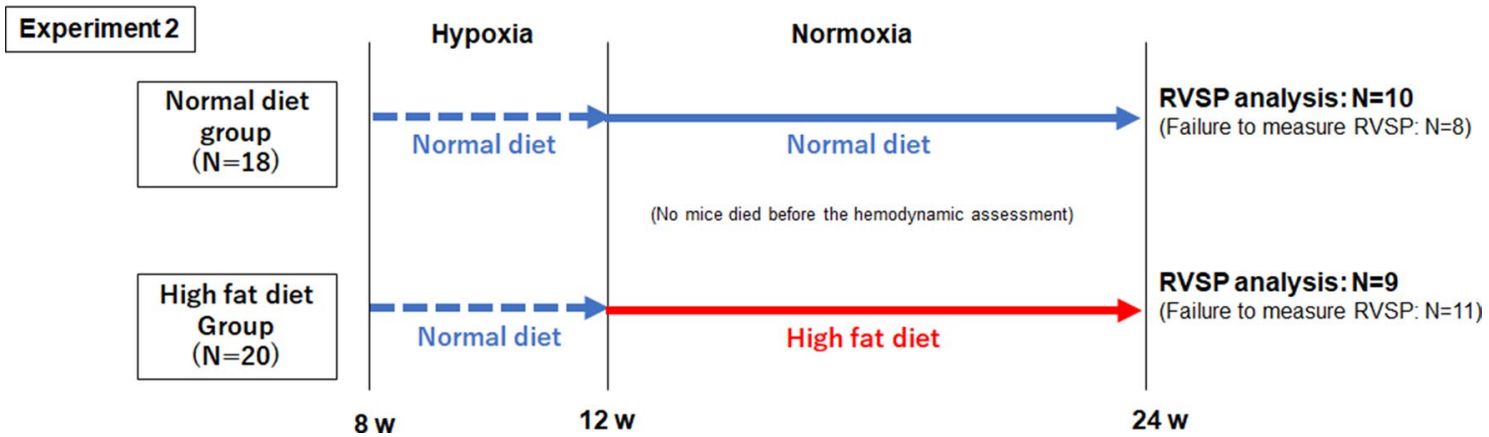

Fig. 1 Experimental groups and protocols in mice. In experiment 1, the mice were exposed to normoxia or hypoxia with ND for 4 weeks. In experiment 2, the mice were exposed to hypoxic condition for four weeks and divided into ND and HFD group during reoxygenation (normoxia) for 12 weeks 
Table 1 Comparison of diet composition

\begin{tabular}{|c|c|c|}
\hline & ND & HFD \\
\hline \multicolumn{3}{|l|}{ Nutrient components and calories } \\
\hline Moisture (\%) & 8.48 & 6.2 \\
\hline Crude protein (\%) & 27.09 & 25.5 \\
\hline Crude fat (\%) & 4.69 & 32.0 \\
\hline Crude fiber (\%) & 4.54 & 2.9 \\
\hline Crude ash (\%) & 7.92 & 4.0 \\
\hline Nitrogen free extracts (\%) & 47.2 & 29.4 \\
\hline Energy (kcal) & 339.7 & 507.6 \\
\hline \multicolumn{3}{|c|}{ Fatty acid composition (relative percentage to the total fatty acid) } \\
\hline Total (\%) & 100.0 & 100 \\
\hline Saturated fatty acid (\%) & 21.05 & 22.3 \\
\hline Monosaturated fatty acid (\%) & 28.47 & 66.5 \\
\hline Polyunsaturated fatty acid (\%) & 47.13 & 10.4 \\
\hline Myristic acid (\%) & 1.51 & 1.1 \\
\hline Myristoleic acid (\%) & - & 0.3 \\
\hline Pentadecanoic acid (\%) & - & 0.1 \\
\hline Palmitic acid (\%) & 16.71 & 1.2 \\
\hline Palmitoleic acid (\%) & 2.46 & 0.4 \\
\hline Heptadecanoic acid (\%) & 1.08 & 0.4 \\
\hline Heptadecenoic acid (\%) & - & 0.3 \\
\hline stearic acid (\%) & 2.45 & 7.5 \\
\hline oleic acid (\%) & 20.35 & 64.3 \\
\hline Elaidic acid (\%) & 0.18 & - \\
\hline Vaccenic acid (\%) & 3.29 & - \\
\hline Linoleic acid (\%) & 36.37 & 10.2 \\
\hline a-Linolenic acid (\%) & 3.08 & 0.2 \\
\hline Arachidic acid (\%) & - & 0.3 \\
\hline Icosenoic acid (\%) & 0.84 & 0.3 \\
\hline Arachidonic acid (\%) & 0.18 & - \\
\hline Eicosapentaenoic acid (\%) & 5.23 & - \\
\hline Behenic acid (\%) & 0.20 & 0.2 \\
\hline Docosahexaenoic acid (\%) & 2.27 & - \\
\hline Lignoceric acid (\%) & 0.18 & - \\
\hline Tetracosenoic acid (\%) & 0.27 & - \\
\hline Unidentified (\%) & 3.35 & 0.26 \\
\hline
\end{tabular}

$N D$ normal diet, $H F D$ high-fat diet

was 62. The mice in all groups were treated at once, and each group was allocated in each cage. After we unified the cage locations, we randomly measured the RVSP to avoid the effect of the order of animals and cages.

\section{Measurements of right ventricular pressure and ventricular weight}

Intraperitoneal injection of anesthesia was done using Tribromoethanol $\left(0.25 \mathrm{mg} / \mathrm{g}\right.$ of body weight). At $21 \% \mathrm{O}_{2}$ condition, A 1.2-F micromanometer catheter (Transonic Scisense Inc., London, ON, Canada) was inserted to the right jugular vein, and the RVSP was measured without a ventilator and analyzed by LabScribe3 software (IWORX, Dover, NH, USA) [14]. Then, the mice were sacrificed by cervical dislocation; the heart and lungs were removed for $\mathrm{RVH}$ evaluation. The right ventricle (RV) was dissected from the left ventricle (LV), including the septum (S), and the RV/LV $+\mathrm{S}$ weight ratio (Fulton index) was calculated [14, 15]. The mice with severe bleeding or pneumothorax that affected the hemodynamics during catheterization were excluded from the RVSP analysis, as shown in Fig. 1.

\section{Histological analysis}

After measuring the RV pressure, the right lung was fixed with $4 \%$ paraformaldehyde, embedded in paraffin, and sectioned to $3 \mu \mathrm{m}$. After Elastica-Masson (EM) staining or immunostaining of $\alpha$-smooth muscle actin ( $\alpha$-SMA) (Santa Cruz Biotechnology Inc., Santa Cruz, CA, USA), the pulmonary arteries (external diameter of $20-50 \mu \mathrm{m}$ ) were randomly selected (60-90 vessels per individual mouse). The medial wall area (the area between the internal and external lamina) was measured using the Image J 1.48 software (National Institutes of Health, Bethesda, MD, USA) and divided by the vessel area (the area surrounded by the external lamina) [14, 15]. Furthermore, each vessel (external diameter of $<20 \mu \mathrm{m}$ ) was classified as non-muscular, partially muscular, or fully muscular, as described in a previous report. The percentage of muscularized pulmonary vessels was determined by dividing the sum of partially and fully muscular vessels by the total number of vessels [14]. Measurements were performed blinded to the mouse information.

\section{Lipids profiles}

The plasma from mice at 24 weeks was isolated by centrifugation (3000 rpm, $15 \mathrm{~min}$ ), frozen at $-80{ }^{\circ} \mathrm{C}$, and analyzed by Nagahama Life Science Laboratory (Shiga, Japan). The plasma concentrations of high-density lipoprotein cholesterol (HDL-C) and low-density lipoprotein cholesterol (LDL-C) were measured by direct method using Chorestest $\mathrm{N} \mathrm{HDL}^{\circledR}$ (Sekisui Medical Co., Ltd. Tokyo, Japan) and Chorestest LDL $^{\circledR}$ (Sekisui Medical). The plasma triglyceride (TG) was measured by enzymatic method using L-type Wako TG.M ${ }^{\circledR}$ (FUJIFILM Wako Pure Chemical Corporation. Osaka, Japan).

\section{Measurements of mitochondrial ATP}

To evaluate the mitochondrial function, we measured the mitochondrial adenosine triphosphate (ATP) in the lungs based on a previous study [4]. The removed left lung was homogenized, and the mitochondrial fraction was isolated by centrifugation. Then, the ATP production was measured using a commercially available kit (TOYO 
B-Net Co., Ltd. Tokyo, Japan), following the manufacturer's instruction.

\section{Mitochondrial DNA quantification}

Mitochondrial DNA was quantified as described previously [16]. The DNA from the left lung was extracted and purified by QIAamp DNA Mini Kit (Qiagen, Hilden, Germany) according to the manufacturer's instruction, with the inclusion of RNAse A digest. Quantitative polymerase chain reaction (PCR) was performed using the power SYBR green PCR master mix with a CFX Connect real-time PCR System (Bio-Rad Laboratories, Inc., Hercules, CA) using mitochondrial DNA-specific primer, cytochrome oxidase subunit 1 (Co1) gene, nuclear DNAspecific primer, and NADH:Ubiquinone oxidoreductase core subunit V1 (NDUFV1). The sequences of primers were as follows: forward $5^{\prime}$-TGCTAGCCGCAGGCA TTAC- $3^{\prime}$ and reverse $5^{\prime}$-GGGTGCCCAAAGAATCAG AAC-3' for Co1, and forward 5'-CTTCCCCACTGG CCTCAAG- $3^{\prime}$ and reverse $5^{\prime}$-CCAAAACCCAGTGAT CCAGC-3' for NDUFV1. All reactions were run in duplicates. The mitochondrial DNA content was calculated using the delta CT method, and the data were expressed as a fold increase in the ND group.

\section{Western blotting}

The removed whole left lungs were used for western blotting, which was performed as described previously [17, 18]. Polyvinylidene difluoride membranes were incubated with mouse monoclonal antibodies to $\beta$-actin (Santa Cruz) and heme oxygenase-1 (HO-1) (Novus Biologicals USA, Littleton, CO, USA) diluted to 1:1000 for $1 \mathrm{~h}$ at room temperature. Rabbit polyclonal antibodies to active caspase-3 (Cell Signaling Technology, Beverly, MA, USA), PPAR- $\gamma$ (Cell Signaling Technology), voltage-dependent anion channel (VDAC) (Cell Signaling Technology), hypoxia-inducible factor- $1 \alpha$ (HIF-1 $\alpha$ ) (Cell Signaling Technology), and apelin (Bioss Inc, Boston, MA, USA) were diluted to 1:500. Then, each membrane was incubated with a horseradish peroxidase-conjugated secondary antibody or IRDye ${ }^{\circledR} 680$ RD or IRDye ${ }^{\circledR} 800 \mathrm{CW}$ (LI-COR, Inc., Lincoln, NE, USA) diluted to 1:10,000 for $45 \mathrm{~min}$.

\section{Apoptosis of pulmonary smooth muscle cells}

To estimate the apoptosis of pulmonary smooth muscle cells, terminal deoxynucleotidyl transferase-mediated dUTP nick end-labeling (TUNEL) assay was performed by $\mathrm{CF}^{\mathrm{TM}}$ 640R TUNEL Assay Apoptosis Detection Kit (Biotium, Hayward, CA, USA), following the manufacturer's instructions. $\alpha$-SMA was detected by immunofluorescent staining using an antibody against $\alpha$-SMA (Santa Cruz) and Alexa Fluor 488-conjugated goat anti-mouse secondary IgG (Abcam, Cambridge, United Kingdom). The samples were mounted with ProLong Gold Antifade Reagent with DAPI (Thermo Fisher Scientific, Waltham, MA, USA). Fluorescence was observed with an immunofluorescence microscope (BZ-X700, KEYENCE Co., Osaka, Japan). We randomly selected at least 10 fields in each specimen and counted the nuclei in the medial smooth muscle layer. The results were expressed as percentages of the number of TUNEL-positive nuclei over the total number of nuclei [14].

\section{Statistical analysis}

The data are expressed as mean \pm SEM, and statistical analysis was performed using either Student's t-test or one-way ANOVA with Tukey's multiple comparison test. A value of $P<0.05$ was considered statistically significant.

\section{Results}

\section{Effect of hypoxia on RVSP and RVH}

In experiment 1 , we confirmed the effect of hypoxia exposure on RVSP, RVH, and medial thickening at 12 weeks. Both RVSP and Fulton index are elevated in response to hypoxia (Fig. 2A, B). The medial smooth muscle layer of the hypoxia-exposed mice was significantly greater than that of the normoxia-exposed mice (Fig. 2C). Western blot demonstrated that PPAR- $\gamma$ expression in the normoxia and hypoxia group is comparable, whereas the lung tissue apelin of hypoxia-exposed mice is higher than that of normoxia-exposed mice (Fig. 1D, E). The active caspase- 3 in the whole lung tissue of hypoxia-exposed mice is increased. TUNEL staining showed that smooth muscle cell apoptosis is decreased in hypoxia-exposed mice (Fig. 1F, G).

\section{Effect of HFD on hypoxia-induced PH mice during reoxygenation}

Figure 3A shows that the body weight in the HFD group is significantly heavier than that in the ND group at 24 weeks in Experiment 2. Glucose, LDL-C, and HDL-C, but not TG, in the HFD group are significantly higher than those in the ND group (Fig. 3B). There is a significant difference in the RVSP of the ND and HFD groups at 24 weeks; that in the ND group almost recovered to normal level, whereas that in the HFD group did not (Fig. 3C). The RV weight and Fulton index in the HFD group are larger than those in the ND group, whereas the LV weight is comparable between the groups (Fig. 3D). Figure 3E shows the mitochondrial ATP levels in the lung tissues. The mitochondrial ATP in the HFD group is higher than that in the ND group. However, mitochondrial DNA 


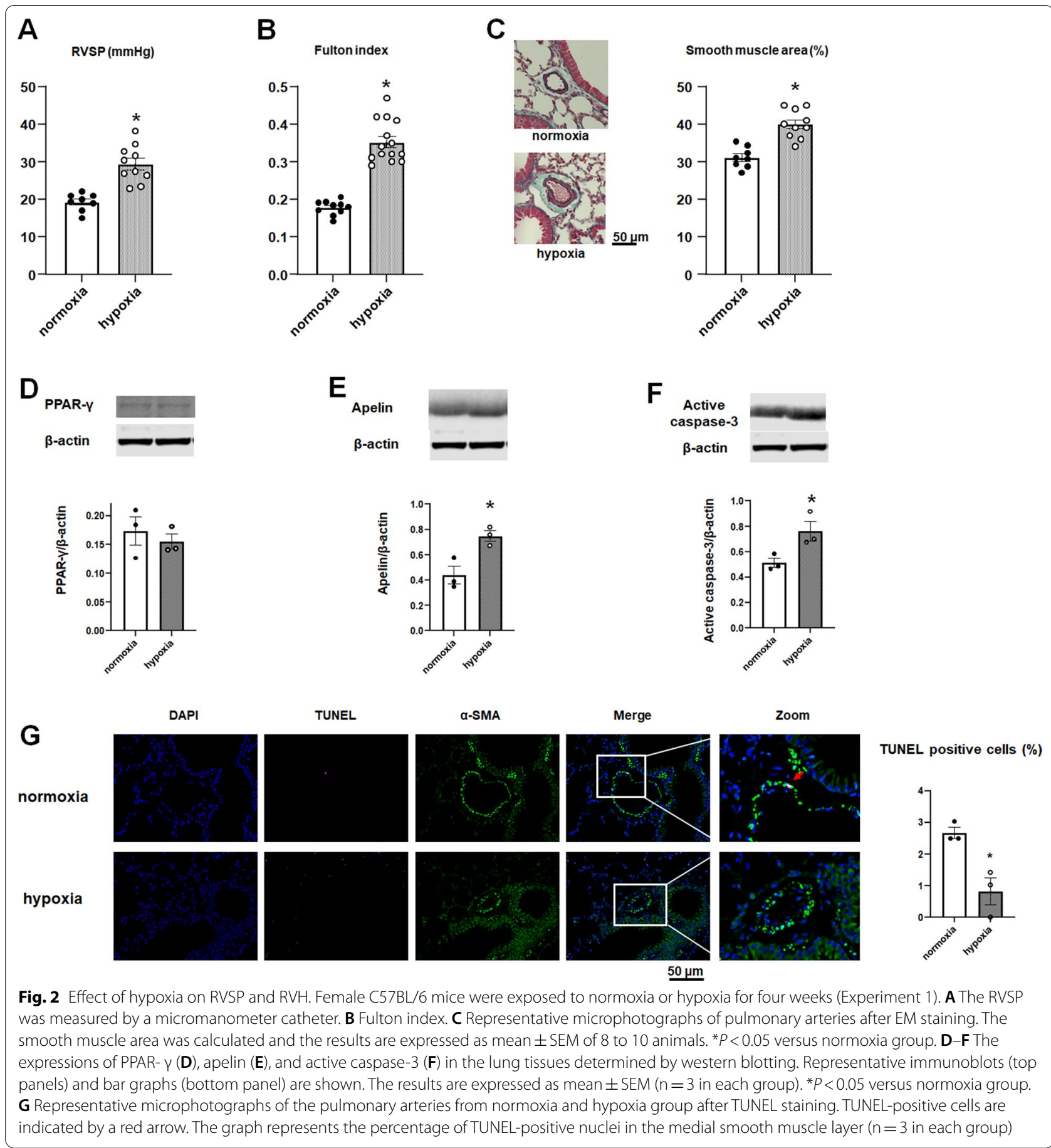

and amounts of mitochondrial mass reflected by VDAC expression were equivalent between the groups (Fig. 3E).

\section{HFD delays reverse remodeling of pulmonary arteries}

In the ND group, the hypoxia-induced medial wall thickening of the pulmonary arteries almost normalized at 24 weeks, whereas it remained significantly high in the HFD group (Fig. 4A, left and middle panels). The proportion of fully muscular vessels in the HFD group is significantly higher than that in the ND group. The percentages of partially muscular vessels are nearly equivalent between the two groups (Fig. 4A, right panel). Western blotting demonstrated that caspase- 3 activity is decreased in the lung tissue of the HFD group (Fig. 4B). TUNEL staining 


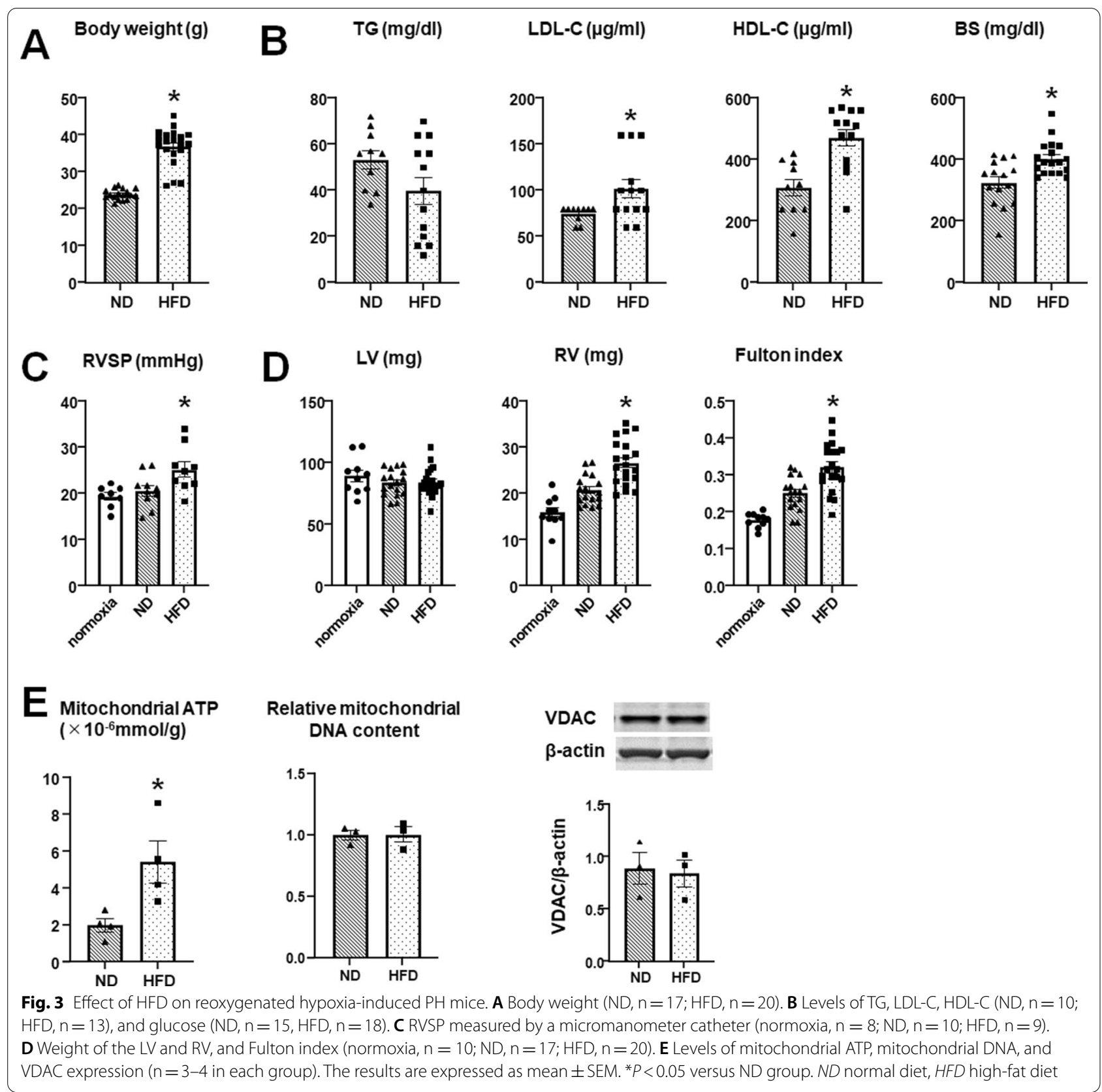

shows that pulmonary artery smooth muscle cell apoptosis in the HFD group is lower than that in the ND group (Fig. 4C). Moreover, the levels of PPAR- $\gamma$ and apelin are lower in the lung tissue of the HFD group (Fig. 4D, E). There are no significant differences in the levels of HO-1 between the ND group and HFD group (Fig. 4F). HIF-1 $\alpha$ is increased in the HFD group, but it is not statistically significant (Fig. 4G).

\section{Discussion}

In this study, HFD suppressed pulmonary artery reverse remodeling and RVSP and RVH improvements in hypoxia-induced $\mathrm{PH}$ mice during reoxygenation. One of the possible mechanisms is the undiminished antiapoptotic pulmonary smooth muscle cells and reduced PPAR- $\gamma$ and apelin levels in the HFD group. Although there have been several studies reporting that metabolic disorders are associated with the onset and progression of $\mathrm{PH}$ in experimental models [19-21], this study is the 


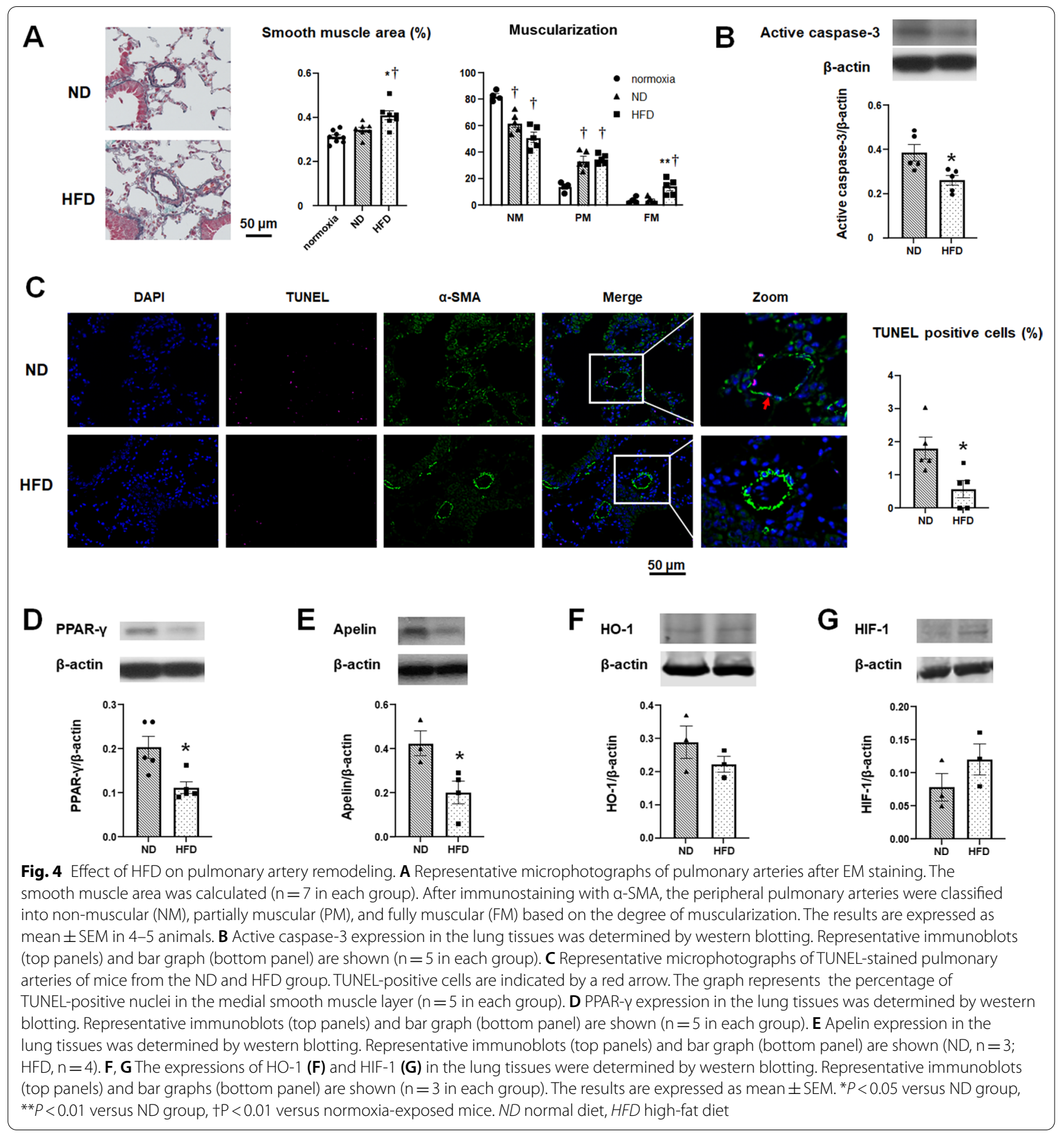

first to show that HFD affects the improvement process of $\mathrm{PH}$ after reoxygenation.

Recently, Umar et al. reported that a western diet increased the lung inflammation, leading to the development of PH in LDL receptor-knockout mice [22]. In this study, although inflammatory changes were not examined, TUNEL-positive cells in pulmonary artery smooth muscle cells and lung caspase- 3 activity were more decreased in the HFD group than in the ND group. Since the role of native or oxidized LDL for smooth muscle cell apoptosis or proliferation is controversial [22-26], further studies are needed.

In this study, the HFD group presented higher RVSP and HDL-C levels than the ND group; however, previous studies have shown an association of higher plasma HDL-C levels with good prognosis in human PH $[27,28]$. 
However, the detailed underlying mechanisms responsible for the beneficial effects of HDL-C in pulmonary circulation are not fully explored [28], and a multicenter prospective cohort study by Cracowski et al. showed that HDL-C was not associated with survival from PH [29]. Thus, the role of HDL-C level in PH remains unclear.

Furthermore, Umar et al. showed that a western diet affects left ventricular systolic pressure and RVSP [22]. However, in this study, HFD did not affect the least left ventricular weight.

Chen et al. revealed that mitochondrial dysfunction represented by decreased lung ATP production induces hydrogen peroxide generation and is necessary for smooth muscle cell apoptosis in reverse remodeling during reoxygenation in hypoxia-induced $\mathrm{PH}$ mice [4]. This study showed that mitochondrial ATP production was higher in the HFD group than in the ND group. This suggests the possibility that the improvement in mitochondrial function by HFD may have acted suppressively on reverse remodeling. Although HIF- $1 \alpha$ is known to inhibit ATP production, there was no significant difference in HIF- $1 \alpha$ expression between the ND group and HFD group. In addition, $\mathrm{HO}-1$, as a marker of oxidative stress, was also comparable in spite of the different mitochondrial ATP level. Further mechanisms are needed to be elucidated for these results.

$\mathrm{PH}$ patients are reported to have lower levels of plasma apelin, and the administration of apelin agonist improved the hemodynamics in PH patients [11, 30, 31]. A G-protein-coupled receptor, APJ, and its ligand, apelin, are highly expressed in the pulmonary vasculature. It has been reported that apelin-deficient mice develop more severe $\mathrm{PH}$ than the wild-type when exposed to hypoxia. Apelin signals are involved in the activation of AMP-activated kinase, Kruppel-like factor 2, and endothelial nitric oxide synthase, and their reduction is thought to reduce nitric oxide-dependent vasodilatation and exacerbate $\mathrm{PH}[30,32]$. Apelin is regulated by PPAR $-\gamma[11]$; thus, it is suggested that the decreased PPAR- $\gamma$ in reoxygenated HFD mice causes the downregulation of apelin and delays pulmonary vasculature reverse remodeling.

In this study, the ratios of monounsaturated fatty acids/ polyunsaturated fatty acids (PUFA) and $n-6 / n-3$ in the diet used in the HFD group were significantly higher than those in the ND group. Previous reports have shown that diets richer in n-3 PUFA suppress pulmonary arterial wall thickening in rats [33]. In addition, the n-3 PUFA enhanced the dilatation of pulmonary vessels through decreased thromboxane $A_{2}$, prostaglandin $E_{2}$, leukotriene $\mathrm{B}_{4}$, and interleukin 6 , and increased thromboxane $A_{3}$, prostaglandin $I_{2}$, and leukotriene $B_{5}$ [34]. Conversely, n-6 PUFAs have proinflammatory effects. Collectively, it is speculated that the relative increase in $n-6 / n-3$ PUFA in this study may have led to decreased pulmonary vasodilatory effects and increased inflammation, leading to delayed reverse remodeling of the pulmonary arteries.

Until now, the effectiveness of lipid-lowering therapy for pulmonary arterial hypertension (PAH) in previous studies has been controversial despite the association between metabolic disorder and $\mathrm{PH}$ [35-37]. In fact, it is confirmed that an intervention for dyslipidemia is less effective than the use of pulmonary vasodilators. However, even though pulmonary vasodilators dramatically improve the prognosis of PAH patients [38], there are cases in which these drugs cannot be used due to side effects. On the other hand, in patients with $\mathrm{PH}$ associated with chronic lung disease, pulmonary vasodilator sometimes induces hypoxia due to ventilation/perfusion mismatch. Therefore, it is necessary to establish a treatment other than vasodilator therapy. In addition, we believe that with the improvement in the prognosis of $\mathrm{PH}$ patients, the complications of metabolic disorders increase. The results suggest that the treatment for metabolic disorder, in addition to pulmonary vasodilator, has a supportive effect to improve $\mathrm{PH}$.

\section{Conclusions}

In conclusion, this study reports for the first time that a HFD delays the reverse remodeling of the pulmonary arteries of mice with hypoxia-induced $\mathrm{PH}$. Metabolic disorder in $\mathrm{PH}$ patients may require active treatment to improve pulmonary artery pressure as soon as possible.

\section{Abbreviations}

PH: Pulmonary hypertension; PPAR-ү: Peroxisome proliferator-activated receptor- $\gamma$; HFD: High-fat diet; RVSP: Right ventricular systolic pressure; RVH: Right ventricular hypertrophy; ND: Normal diet; RV: Right ventricle; LV: Left ventricle; S: Septum; EM: Elastica-Masson; a-SMA: a-Smooth muscle actin; HDL-C: High-density lipoprotein cholesterol; LDL-C: Low-density lipoprotein cholesterol; TG: Triglyceride; ATP: Adenosine triphosphate; TUNEL: Terminal deoxynucleotidyl-transferase-mediated dUTP nick end-labeling; PCR: Polymerase chain reaction; HO-1: Heme oxygenase-1; VDAC: Voltage-dependent anion channel; HIF-1a: Hypoxia inducible factor-1a.

\section{Supplementary Information}

The online version contains supplementary material available at https://doi. org/10.1186/s12872-021-02143-x.

Additional file 1. The ARRIVE guidelines 2.0: author checklist.

Acknowledgements

Not applicable.

Authors' contributions

Conception: KS and YT. Design of the work: KS and YT. Acquisition of data: KS and TY. Analysis and interpretation of data: KS, TM, TK, and AY. Manuscript 
writing: $\mathrm{KS}$, and $\mathrm{YT}$. Review and editing: $\mathrm{KN}$ and $\mathrm{YT}$. All authors have read and approved the final manuscript.

\section{Funding}

None.

\section{Availability of data and materials}

All data generated or analyzed during this study are included in this published article.

\section{Declarations}

\section{Ethics approval and consent to participate}

This study does not involve human participants, human material, or human data. All animal experiments were performed in compliance with the Fukushima Medical University Animal Research Committee. The investigations conformed to the Guidelines for the Care and Use of Laboratory Animals published by the US National Institutes of Health (NIH publication, 8th Edition, 2011), and our research protocol was approved by the Fukushima Medical University Animal Research Committee. The study on animals was carried out in compliance with the ARRIVE guidelines.

\section{Consent for publication}

Not Applicable.

\section{Competing interests}

Koichi Sugimoto and Tetsuro Yokokawa belong to a department supported by Janssen Pharmaceutical K.K. This company was not associated with the contents of this study. Tomofumi Misaka, Takashi Kaneshiro, Akiomi Yoshihisa, Kazuhiko Nakazato and Yasuchika Takeishi have no competing interests as defined by BMC.

\section{Author details}

${ }^{1}$ Department of Cardiovascular Medicine, Fukushima Medical University, Hikarigaoka 1, Fukushima 960-1295, Japan. ${ }^{2}$ Department of Pulmonary Hypertension, Fukushima Medical University, Hikarigaoka 1, Fukushima 960-1295, Japan.

Received: 1 January 2021 Accepted: 14 June 2021

Published online: 06 July 2021

\section{References}

1. Zhu L, Liu F, Hao Q, Feng T, Chen Z, Luo S, et al. Dietary geranylgeranyl pyrophosphate counteracts the benefits of statin therapy in experimental pulmonary hypertension. Circulation. 2021. https://doi.org/10.1161/ CIRCULATIONAHA.120.046542.

2. Voelkel NF, Tuder RM. Hypoxia-induced pulmonary vascular remodeling: a model for what human disease? J Clin Invest. 2000;106(6):733-8.

3. Shimoda LA, Laurie SS. Vascular remodeling in pulmonary hypertension. J Mol Med (Berl). 2013;91(3):297-309.

4. Chen J, Wang YX, Dong MQ, Zhang B, Luo Y, Niu W, et al. Reoxygenation reverses hypoxic pulmonary arterial remodeling by inducing smooth muscle cell apoptosis via reactive oxygen species-mediated mitochondrial dysfunction. J Am Heart Assoc. 2017;6(6):e005602.

5. Sluiter I, van Heijst A, Haasdijk R, Kempen MB, Boerema-de Munck A, Reiss I, et al. Reversal of pulmonary vascular remodeling in pulmonary hypertensive rats. Exp Mol Pathol. 2012;93(1):66-73.

6. Riley DJ, Thakker-Varia S, Wilson FJ, Poiani GJ, Tozzi CA. Role of proteolysis and apoptosis in regression of pulmonary vascular remodeling. Physiol Res. 2000:49:577-85.

7. Ussavarungsi K, Thomas CS, Burger CD. Prevalence of metabolic syndrome in patients with pulmonary hypertension. Clin Respir J. 2017;11(6):721-6

8. Maron BA, Leopold JA, Hemnes AR. Metabolic syndrome, neurohumoral modulation, and pulmonary arterial hypertension. Br J Pharmacol. 2020;177(7):1457-71.

9. Calvier L, Boucher P, Herz J, Hansmann G. LRP1 Deficiency in vascular SMC leads to pulmonary arterial hypertension that is reversed by PPARy activation. Circ Res. 2019;124(12):1778-85.
10. Yeligar SM, Kang BY, Bijli KM, Kleinhenz JM, Murphy TC, Torres G, et al. PPARY regulates mitochondrial structure and function and human pulmonary artery smooth muscle cell proliferation. Am J Respir Cell Mol Biol. 2018;58(5):648-57.

11. Alastalo TP, Li M, Perez Vde J, Pham D, Sawada H, Wang JK, et al. Disruption of PPAR $/ \beta$-catenin-mediated regulation of apelin impairs BMPinduced mouse and human pulmonary arterial EC survival. J Clin Invest. 2011;121(9):3735-46.

12. Keleher MR, Zaidi R, Shah S, Oakley ME, Pavlatos C, El Idrissi S, Xing X, Li D, Wang T, Cheverud JM. Maternal high-fat diet associated with altered gene expression, DNA methylation, and obesity risk in mouse offspring. PLOS ONE. 2018;13(2):e0192606.

13. Novelli EM, Little-lhrig L, Knupp HE, Rogers NM, Yao M, Baust JJ, Meijles D, St Croix CM, Ross MA, Pagano PJ, DeVallance ER, Miles G, Potoka KP, Isenberg JS, Gladwin MT. Vascular TSP1-CD47 signaling promotes sickle cell-associated arterial vasculopathy and pulmonary hypertension in mice. Am J Physiol Lung Cell Mol Physiol. 2019;316(6):L1150-64.

14. Sugimoto K, Nakazato K, Sato A, Suzuki S, Yoshihisa A, Machida T, et al. Autoimmune disease mouse model exhibits pulmonary arterial hypertension. PLoS ONE. 2017;12(9):e0184990.

15. Nakanishi N, Ogata T, Naito D, Miyagawa K, Taniguchi T, Hamaoka T, et al. MURC deficiency in smooth muscle attenuates pulmonary hypertension. Nat Commun. 2016;7:12417.

16. Misaka T, Murakawa T, Nishida K, Omori Y, Taneike M, Omiya S, et al. FKBP8 protects the heart from hemodynamic stress by preventing the accumulation of misfolded proteins and endoplasmic reticulum-associated apoptosis in mice. J Mol Cell Cardiol. 2018;114:93-104.

17. Sakamoto T, Ishibashi T, Sakamoto N, Sugimoto K, Egashira K, Ohkawara $\mathrm{H}$, et al. Endogenous NO blockade enhances tissue factor expression via increased Ca2 + influx through MCP-1 in endothelial cells by monocyte adhesion. Arterioscler Thromb Vasc Biol. 2005;25(9):2005-11.

18. Sugimoto K, Ishibashi T, Sawamura T, Inoue N, Kamioka M, Uekita H, et al. LOX-1-MT1-MMP axis is crucial for RhoA and Rac1 activation induced by oxidized low-density lipoprotein in endothelial cells. Cardiovasc Res. 2009;84(1):127-36.

19. Irwin DC, Garat CV, Crossno JT Jr, MacLean PS, Sullivan TM, Erickson PF, et al. Obesity-related pulmonary arterial hypertension in rats correlates with increased circulating inflammatory cytokines and lipids and with oxidant damage in the arterial wall but not with hypoxia. Pulm Circ 2014:4(4):638-53.

20. Renshall L, Arnold N, West L, Braithwaite A, Pickworth J, Walker R, et al. Selective improvement of pulmonary arterial hypertension with a dual ETA/ETB receptors antagonist in the apolipoprotein E-/- model of PAH and atherosclerosis. Pulm Circ. 2018;8(1):2045893217752328.

21. Pan M, Han Y, Si R, Guo R, Desai A, Makino A. Hypoxia-induced pulmonary hypertension in type 2 diabetic mice. Pulm Circ. 2017;7(1):175-85.

22. Umar S, Ruffenach G, Moazeni S, Vaillancourt M, Hong J, Cunningham C, et al. Involvement of low-density lipoprotein receptor in the pathogenesis of pulmonary hypertension. J Am Heart Assoc. 2020;9(2):e012063.

23. Hsieh CC, Yen MH, Yen CH, Lau YT. Oxidized low density lipoprotein induces apoptosis via generation of reactive oxygen species in vascular smooth muscle cells. Cardiovasc Res. 2001;49(1):135-45.

24. Kattoor AJ, Kanuri SH, Mehta JL. Role of Ox-LDL and LOX-1 in atherogenesis. Curr Med Chem. 2019;26(9):1693-700.

25. Locher R, Brandes RP, Vetter W, Barton M. Native LDL induces proliferation of human vascular smooth muscle cells via redox-mediated activation of ERK 1/2 mitogen-activated protein kinases. Hypertension. 2002;39(2 Pt 2):645-50.

26. Damián-Zamacona S, Toledo-Ibelles $\mathrm{P}$, Ibarra-Abundis $\mathrm{MZ}$, Uribe-Figueroa L, Hernández-Lemus E, Macedo-Alcibia KP, et al. Early transcriptomic response to LDL and oxLDL in human vascular smooth muscle cells. PLoS ONE. 2016;11(10):e0163924

27. Heresi GA, Aytekin M, Newman J, DiDonato J, Dweik RA. Plasma levels of high-density lipoprotein cholesterol and outcomes in pulmonary arterial hypertension. Am J Respir Crit Care Med. 2010;182(5):661-8.

28. Jonas K, Kopeć G. HDL cholesterol as a marker of disease severity and prognosis in patients with pulmonary arterial hypertension. Int J Mol Sci. 2019:20(14):3514

29. Cracowski JL, Labarère J, Renversez JC, Degano B, Chabot F, Humbert M. Plasma levels of high-density lipoprotein cholesterol are not associated 
with survival in pulmonary arterial hypertension. Am J Respir Crit Care Med. 2012;186(1):107 author reply 107-8.

30. Andersen CU, Hilberg O, Mellemkjær S, Nielsen-Kudsk JE, Simonsen U. Apelin and pulmonary hypertension. Pulm Circ. 2011;1 (3):334-46.

31. Brash L, Barnes GD, Brewis MJ, Church AC, Gibbs SJ, Howard LSGE, et al. Short-term hemodynamic effects of apelin in patients with pulmonary arterial hypertension. JACC Basic Transl Sci. 2018;3(2):176-86.

32. Chandra SM, Razavi H, Kim J, Agrawal R, Kundu RK, de Jesus Perez V, et al. Disruption of the apelin-APJ system worsens hypoxia-induced pulmonary hypertension. Arterioscler Thromb Vasc Biol. 2011;31(4):814-20.

33. Archer SL, Johnson GJ, Gebhard RL, Castleman WL, Levine AS, Westcott JY, et al. Effect of dietary fish oil on lung lipid profile and hypoxic pulmonary hypertension. J Appl Physiol (1985). 1989;66(4):1662-73.

34. Ciomartan TC. The n-3 polyunsaturated fatty acids: another option in the management of persistent pulmonary hypertension of the newborn? Crit Care Med. 2011;39(6):1587-9.

35. Rysz-Górzynska M, Gluba-Brzózka A, Sahebkar A, Serban MC, Mikhailidis DP, Ursoniu S, et al. Efficacy of statin therapy in pulmonary arterial hypertension: a systematic review and meta-analysis. Sci Rep. 2016;6:30060.

36. Anand V, Garg S, Duval S, Thenappan T. A systematic review and metaanalysis of trials using statins in pulmonary arterial hypertension. Pulm Circ. 2016;6(3):295-301.

37. Chen F, Yang M, Wan C, Liu L, Chen L. Efficacy and safety of statin therapy in pulmonary hypertension: a systematic review and meta-analysis. Ann Transl Med. 2019;7(23):786.

38. Ogawa A, Ejiri K, Matsubara H. Long-term patient survival with idiopathic heritable pulmonary arterial hypertension treated at a single center in Japan. Life Sci. 2014;118(2):414-9.

\section{Publisher's Note}

Springer Nature remains neutral with regard to jurisdictional claims in published maps and institutional affiliations.
Ready to submit your research? Choose BMC and benefit from:

- fast, convenient online submission

- thorough peer review by experienced researchers in your field

- rapid publication on acceptance

- support for research data, including large and complex data types

- gold Open Access which fosters wider collaboration and increased citations

- maximum visibility for your research: over 100M website views per year

At BMC, research is always in progress.

Learn more biomedcentral.com/submissions 